\title{
Elevated Faecal Calprotectin in Patients with a Normal Colonoscopy: Does It Matter in Clinical Practice? A Retrospective Observational Study
}

\author{
Henrik Hovstadius David Lundgren Pontus Karling \\ Department of Public Health and Clinical Medicine, Division of Medicine, Umeå University, Umeå, Sweden
}

\section{Keywords}

Faecal calprotectin - Colonoscopy · Cardiovascular disease . Colorectal cancer - Diverticular disease - Esophagitis .

Gastritis · Inflammatory bowel disease

\begin{abstract}
Introduction: Faecal calprotectin (FC) is commonly used as a diagnostic tool for patients with gastrointestinal (GI) symptoms. However, there is uncertainty in daily clinical practice how to interpret an elevated FC in patients with a normal colonoscopy. We investigated if patients with a normal colonoscopy but with an elevated FC more often were diagnosed with a Gl disease in a 3-year follow-up period. Methods: Patients referred for colonoscopy $(n=1,263)$ to the Umeå University Hospital endoscopy unit between 2007 and 2013 performed a FC test (CALPRO ${ }^{\circ}$ ) on the day before bowel preparation. A medical chart review was performed on all patients who had normal findings on their colonoscopy ( $n=585$, median age 64 years). Results: Thirty-four percent of the patients ( $n=202$ ) with normal colonoscopy had elevated FC (>50 $\mu \mathrm{g} / \mathrm{g}$ ), and these patients were more frequently diagnosed with upper Gl disease during the follow-up period than patients with normal FC levels (9.9 vs. $4.7 \% ; p=0.015$ ). The upper $\mathrm{Gl}$ diseases were mainly benign (i.e., gastritis). In a binary logistic regression analysis controlling for age, gender, nonsteroid anti-inflammatory drug use, and proton-
\end{abstract}

karger@karger.com www.karger.com/iid

Karger!

GOPEN ACCESS
(C) 2021 The Author(s)

Published by S. Karger AG, Basel

This is an Open Access article licensed under the Creative Commons Attribution-NonCommercial-4.0 International License (CC BY-NC) (http://www.karger.com/Services/OpenAccessLicense), applicable to the online version of the article only. Usage and distribution for commercial purposes requires written permission. pump inhibitor use, there was no difference for a new diagnosis of upper $\mathrm{Gl}$ disease in the follow-up period (multivariate OR 1.70; $95 \% \mathrm{Cl}: 0.77-3.74)$. There was no difference in a new diagnosis of lower $\mathrm{Gl}$ disease (6.4 vs. $5.2 \% ; p=0.545)$ or cardiovascular disease/death (multivariate OR 1.68; $95 \% \mathrm{Cl}$ : 0.83-3.42) in the follow-up period between patients with elevated versus normal FC levels. Conclusions: In patients with a normal colonoscopy, a simultaneously measured increased FC level was not associated with an increased risk for significant $\mathrm{Gl}$ disease during a follow-up period of 3 years.

(c) 2021 The Author(s)

Published by S. Karger AG, Basel

\section{Introduction}

Calprotectin is an intracellular calcium and zinc-binding protein with antibacterial properties, and it is abundant in the cytoplasm of leukocytes, especially in neutrophil granulocytes [1-3]. These characteristics make calprotectin an excellent marker of leukocyte activity, and increased levels of calprotectin haves been measured in response to inflammatory activity in several body fluids such as serum, liquor, and faeces [4].

Faecal calprotectin (FC) has been used to evaluate gut inflammation in clinical practice for nearly 2 decades [3, 5-8]. The FC test is easy to perform, and it is stable in 
Fig. 1. Recruitment of the study popula-

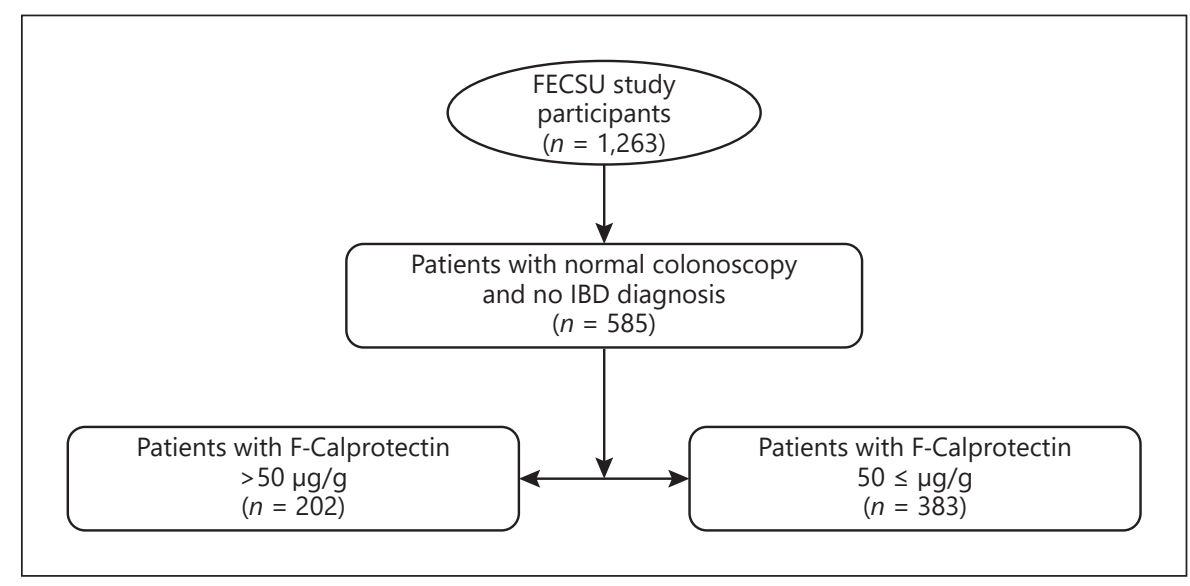

room temperature up to 1 week [9]. The main use of FC is to monitor disease activity in inflammatory bowel diseases (IBDs) and to discriminate IBD from nonorganic bowel disease. FC correlates well with disease activity in IBD, and it can predict relapse and treatment response [10-12]. A normal FC test reduces the need for referral to colonoscopy to evaluate IBD.

In addition to IBD, all factors that trigger the activity and recruitment of neutrophils into the gut lumen can elevate FC levels. For example, elevated FC levels haves been seen in patients with rheumatological disease, necrotizing colitis, infectious colitis, and colorectal carcinoma [13-16]. Elevated FC levels have also been associated with the use of nonsteroid anti-inflammatory drugs (NSAIDs), acetylsalicylic acid (ASA), and proton-pump inhibitors (PPIs) [17-19]. Furthermore, FC levels are affected by age, that is, elevated levels are seen in the elderly as well as in neonates $[19,20]$.

However, in a substantial number of subjects, FC is elevated without any obvious cause. There is uncertainty if these patients are at a higher risk of (or will later develop) gastrointestinal (GI) disease. In the literature, we found only one small report (abstract) that showed that patients with an initially elevated FC, but a normal colonoscopy had a risk of organic disease at follow-up [21].

The aim of the present study was to investigate if a patient in clinical practice with an elevated FC level and without pathological findings on a colonoscopy more often were diagnosed with a significant GI disease in the following 3 years than a patient with normal FC levels. Is it safe to rule out GI disease in a patient with elevated FC but with a normal colonoscopy in clinical practice? A secondary aim was to determine if an elevated FC level was associated with cardiovascular disease and/or death.

\section{Methods}

The present study is based on the Faecal and Endoscopic Colorectal Study in Umeå, Sweden (FECSU), which is a cohort consisting of 1,263 patients [22]. All outpatients that had undergone a planned colonoscopy at the endoscopic unit at Norrlands University Hospital in Umeå between May 2007 and February 2013 were invited to participate in this study. The exclusion criterion in the FECSU was if the colonoscopy was planned to be scheduled in $<1$ week from referral, or if the patient had any impaired mental ability, dementia, or low-performance status that made it difficult to provide a stool sample and/or to fill in the questionnaires. During summer vacations and periods of reorganization at the endoscopic unit, there were temporary stops in the recruitment for the study. In total, there were 2,100 patients invited and 1,263 patients accepted to participate.

In the present study, we included all patients who had a normal outcome of the colonoscopy in the FECSU $(n=585)$ (Fig. 1). Finding of hemorrhoids, colonic diverticulosis, and benign polyps (low-grade adenomas and hyperplastic polyps $<1 \mathrm{~cm}$ ) were classified as having a normal colonoscopy. The adenoma detection rate in the FECSU was $14.5 \%$. Exclusion criteria were known GI diseases including IBD and microscopic colitis. Subjects who were on surveillance for hereditary cancer and patients controlled for previous polyps/cancer were not excluded.

The stool sample was collected the day before the start of bowel preparation and was sent to the accredited Department of Laboratory Medicine, Clinical Chemistry, Umeå University Hospital, on the same day as the colonoscopy was performed. The samples were analyzed using the CALPRO calprotectin ELISA test according to the manufacturer (Calpro AS Norway). The method is not sensitive enough to give specific values below $20 \mu \mathrm{g} / \mathrm{g}$ and above $10,000 \mu \mathrm{g} / \mathrm{g}$. Values out of range were recorded as $<20 \mu \mathrm{g} / \mathrm{g}$ and $>10,000 \mu \mathrm{g} / \mathrm{g}$. Based on the original study by Tibble et al. [5], we used FC level $>50 \mu \mathrm{g} / \mathrm{g}$ to define a positive FC test. All endoscopists who performed colonoscopies in the study and all pathologists were blinded to the result of the FC test. In addition, all patients in the study were asked to report the usage of medications the week before the FC test.

To find patients who had a new diagnosis of any GI disease in the following 3 years, a medical chart review that included the de- 
Table 1. Patients referred to colonoscopy with a normal outcome on the colonoscopy $(n=585)$ and basal characteristics divided by different cutoff values of FC levels

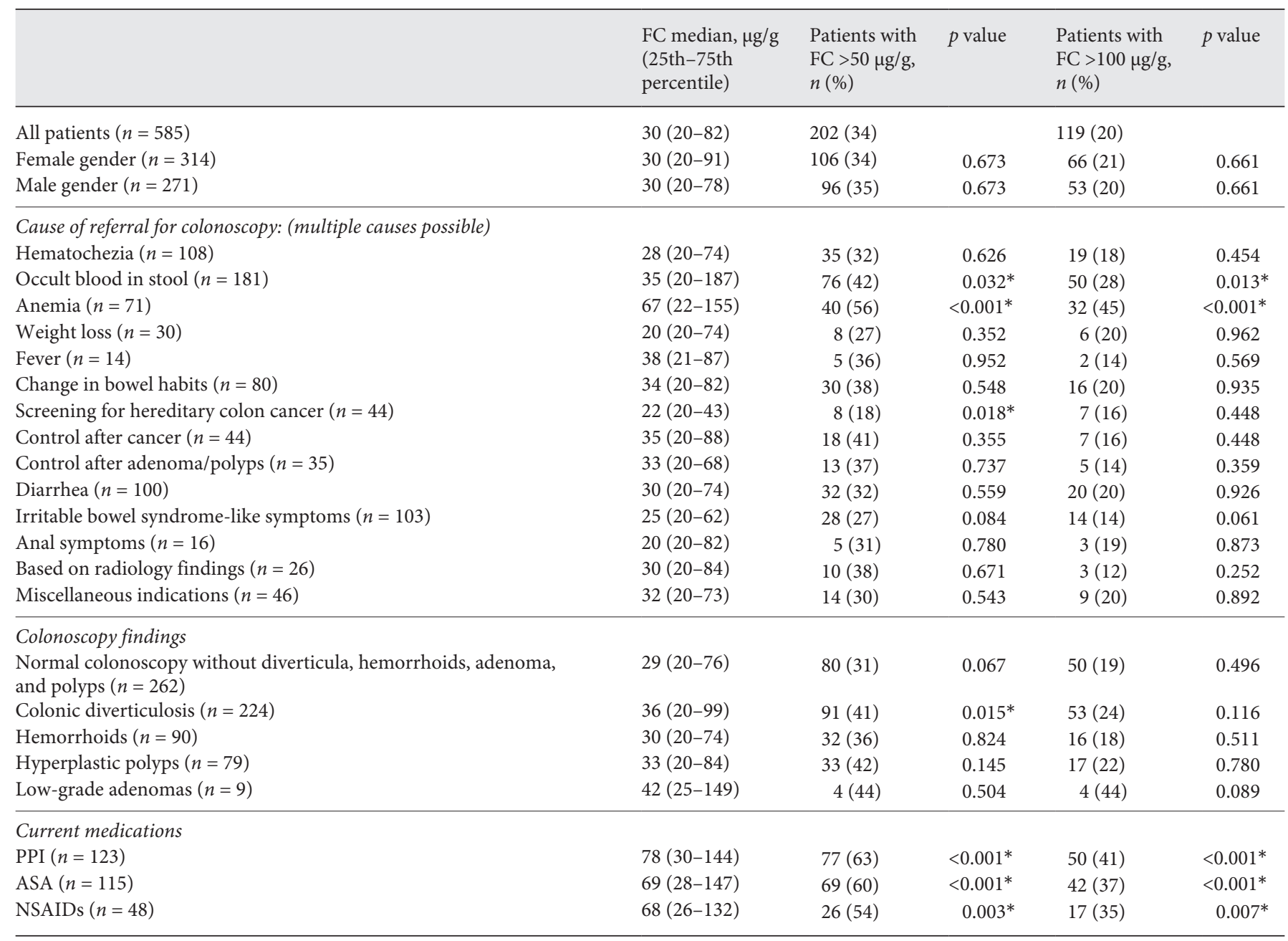

FC, faecal calprotectin; NSAID, nonsteroidal anti-inflammatory drug; PPI, proton-pump inhibitor; ASA, acetylsalicylic acid. * Statistically significant.

partment of medicine, surgery, endoscopy, and radiology was performed on all subjects with a normal index colonoscopy. To construct a composite outcome of major life events, we also checked for cases of death, stroke, or myocardial infarction.

GI disease was classified as either upper or lower GI disease depending on its localization above or below the ligament of Treitz. This is a pragmatic study performed in clinical practice and biopsies for histology were not performed in all patients. Therefore, the definition of GI disease was based on either clinical judgment by the endoscopist or histology as it is done in clinical praxis in Sweden. For example, a patient could be classified as having "gastritis" both on macroscopic (endoscopy) and/or microscopic (histology) judgment.

\section{Statistical Methods}

All statistical analyses were made using IBM SPSS version 26. To compare categorical variables, $\chi^{2}$ tests were used. Fischer's ex- act test was used when the number of subjects with a factor was small $(<10)$. Binary logistical regression was used when controlling for cofounders, and outcomes are presented as odds ratio with 95th confidence intervals. All variables were treated as dichotomous, except age which was treated as a continuous variable. When comparing median age, a Mann-Whitney $U$ test was used. A result was deemed significant if the $p$ value was $<0.05$.

\section{Results}

\section{Patient Characteristics}

All patients who were included in the study were retrospectively observed for 3 years or until deceased. The median age of all patients with a normal colonoscopy was 
Table 2. The number (proportions) of patients with a normal colonoscopy who were diagnosed with GI disease, stroke, myocardial infarction, or deceased within 3 years after the initial colon investigation

\begin{tabular}{lccc}
\hline & $\begin{array}{c}\text { Patients with } \\
\text { FC }>50 \mu \mathrm{g} / \mathrm{g}, \\
n=202\end{array}$ & $\begin{array}{l}\text { Patients with } \\
\text { FC } \leq 50 \mu \mathrm{g} / \mathrm{g}, \\
n=383\end{array}$ & $p$ value \\
& $70(64-75)$ & $60(50-68)$ & $<0.001^{*}$ \\
Median age, years (25th-75th percentile) & $106(52.5 \%)$ & $208(54.3 \%)$ & 0.673 \\
Female gender & $31(15.3 \%)$ & $37(9.7 \%)$ & $0.041^{*}$ \\
Any GI disease & $20(9.9 \%)$ & $18(4.7 \%)$ & $0.015^{*}$ \\
Upper GI disease & $8(4 \%)$ & $8(2.1 \%)$ & 0.187 \\
Gastritis & $6(3 \%)$ & $4(1.0 \%)$ & 0.088 \\
Esophagitis/Barret's esophagus & $3(1.5 \%)$ & $1(0.2 \%)$ & 0.088 \\
Ulcus/Duodenal ulcus & $13(6.4 \%)$ & $20(5.2 \%)$ & 0.545 \\
Lower GI disease & $4(2 \%)$ & $9(2.3 \%)$ & 0.773 \\
Colonic Diverticulitis & $3(1.5 \%)$ & $2(0.5 \%)$ & 0.229 \\
Ileus & $2(1 \%)$ & $6(1.6 \%)$ & 0.570 \\
Any GI cancer & 0 & $2(0.5 \%)$ & $>0.999$ \\
IBD & $24(11.9 \%)$ & $16(4.2 \%)$ & $0.001^{*}$ \\
Death, stroke, and myocardial infarction ${ }^{\mathrm{a}}$ & & & \\
\hline
\end{tabular}

FC, faecal calprotectin; GI, gastrointestinal; IBD, inflammatory bowel disease. ${ }^{\text {a }}$ If a patient suffered either a stroke, myocardial infarction, or died. * Statistically significant.

64 years (25th-75th percentile 53-72 years). There was an equal gender distribution, and the most common cause of referral to colonoscopy was suspicion of GI bleeding (hematochezia, occult blood in stool, and anemia) and IBS-like symptoms (Table 1). Approximately, one-third of the patients had a FC $>50 \mu \mathrm{g} / \mathrm{g}, 1$ of 5 patients had a FC $>100 \mu \mathrm{g} / \mathrm{g}$, and 45 patients (8\%) had a FC $>200 \mu \mathrm{g} / \mathrm{g}$. The median age was significantly higher (70 vs. 60 years; $p<$ $0.001)$ in the $\mathrm{FC}>50 \mu \mathrm{g} / \mathrm{g}$ group than the $\mathrm{FC} \leq 50 \mu \mathrm{g} / \mathrm{g}$ group. There were significantly more patient referred for anemia (54 vs. $32 \% ; p<0.001$ ) and occult blood in the stool ( 42 vs. $31 \%, p<0.032$ ) in the $\mathrm{FC}>50 \mu \mathrm{g} / \mathrm{g}$ group than the FC $\leq 50 \mu \mathrm{g} / \mathrm{g}$ group (Table 1). There were significantly more patients in the group with $\mathrm{FC}>50 \mu \mathrm{g} / \mathrm{g}$ than the group of patients with $\mathrm{FC} \leq 50 \mu \mathrm{g} / \mathrm{g}$ with the finding "colonic diverticulosis" ( 45 vs. $35 \%$; $p=0.015$ ), but there were no differences between the groups in the frequencies of reported hemorrhoids, hyperplastic polyps, and lowgrade adenomas. The use of PPIs (63 vs. $26 \%$; $p<0.001$ ), ASA ( 60 vs. $28 \% ; p<0.001$ ), and NSAIDs ( 54 vs. $33 \%$; $p=0.003$ ) was more common in the $\mathrm{FC}>50 \mu \mathrm{g} / \mathrm{g}$ group than the $\mathrm{FC} \leq 50 \mu \mathrm{g} / \mathrm{g}$ group (Table 1). In the group with patients FC $>50 \mu \mathrm{g} / \mathrm{g}$, there were a significantly lower number of patients referred due to screening for hereditary colonic cancer (18 vs. $36 \%$; $p=0.018$ ).

In the $\mathrm{FC}>100 \mu \mathrm{g} / \mathrm{g}$ group, the median age was significantly higher (70 vs. 62 years; $p<0.001)$ than the FC $\leq 100 \mu \mathrm{g} / \mathrm{g}$ group. There was significantly more patients on PPIs (41 vs. $15 \%$; $p>0.001$ ), ASAs (36 vs. $16 \%$; $p<$ 0.001 ), and NSAIDs (35 vs. $19 \% ; p=0.007$ ) in patients with FC $>100 \mu \mathrm{g} / \mathrm{g}$ than the patients with $\leq 100 \mu \mathrm{g} / \mathrm{g}$. In the FC $>100 \mu \mathrm{g} / \mathrm{g}$ group, there was no significant differences in the frequency of colonic diverticulosis compared to the $\mathrm{FC} \leq 100 \mu \mathrm{g} / \mathrm{g}$ group. The cause of referral for occult blood in the stool (28 vs. $17 \% ; p=0.013$ ) and anemia ( 45 vs. $17 \%$; $p<0.001$ ) was significantly more common in the patients with $\mathrm{FC}>100 \mu \mathrm{g} / \mathrm{g}$ than the patients with FC $\leq 100 \mu \mathrm{g} / \mathrm{g}$.

\section{Gastrointestinal Disease}

The number of patients that during the post-colonoscopy 3 -year observation period underwent any additional GI investigations was 182 (31\%), a second colonoscopy 77 (13\%), a gastroscopy 88 (15\%), a video capsule small bowel endoscopy 10 (1.7\%), an abdominal CT scan 127 (22\%), and other abdominal imaging 20 (3.4\%). There was a significant higher proportion of patients with FC $>50 \mu \mathrm{g} / \mathrm{g}$ than patients with $\mathrm{FC} \leq 50 \mu \mathrm{g} / \mathrm{g}$ that had underwent a second colonoscopy (18 vs. $11 \%$; $p=0.014$ ), gastroscopy ( 22 vs. $11 \% ; p<0.001)$, and abdominal CT scan (31 vs. $17 \% ; p<0.001$ ).

In the 3 -year follow-up period, 68 patients (12\%) had a new diagnosis of any GI disease. Thirty-eight patients were diagnosed with an upper GI disease, 33 patients 
Table 3. The baseline level of FC in patients with a normal colonoscopy that were diagnosed with cancer in the GI tract during a 3-year follow-up period

\begin{tabular}{|c|c|c|c|c|}
\hline GI cancer, $n=8$ & $\begin{array}{l}\text { FC before index } \\
\text { colonoscopy, } \\
\mu \mathrm{g} / \mathrm{g}\end{array}$ & $\begin{array}{l}\text { Gender } \\
\text { (M, male; } \\
\text { F, female) }\end{array}$ & $\begin{array}{l}\text { Age at index } \\
\text { colonoscopy, } \\
\text { years }\end{array}$ & $\begin{array}{l}\text { Time from index } \\
\text { colonoscopy to cancer } \\
\text { diagnosis, months }\end{array}$ \\
\hline Pancreatic cancer & 33 & M & 87 & 7 \\
\hline Recurrence colon cancer, peritoneal carcinosis & 150 & M & 76 & 2 \\
\hline Adenocarcinoma in colon, polyp with cancer & 20 & M & 73 & 28 \\
\hline New liver metastasis from previously treated colorectal cancer & 65 & $\mathrm{~F}$ & 66 & 19 \\
\hline Recurrence of colon cancer with metastasis to mesentery & 47 & $\mathrm{~F}$ & 64 & 6 \\
\hline Cholangiocarcinoma & 20 & $\mathrm{~F}$ & 68 & 10 \\
\hline Adenocarcinoma in appendix & 20 & M & 55 & 12 \\
\hline Carcinoid in small intestine & 35 & M & 79 & 6 \\
\hline
\end{tabular}

FC, faecal calprotectin; GI, gastrointestinal.

were diagnosed with a lower GI disease, and 3 patients developed both upper and lower GI disease. The most common upper GI disease was gastritis $(n=16)$, and the most common lower GI disease was diverticulitis $(n=13)$ (Table 2). The patients with a FC $>50 \mu \mathrm{g} / \mathrm{g}$ were significantly more often diagnosed with an upper GI disease than the patients with FC $\leq 50 \mu \mathrm{g} / \mathrm{g}$, but there was no difference in the occurrence of lower GI disease (Table 2). The most common upper GI disease in the subjects with a FC $>50 \mu \mathrm{g} / \mathrm{g}$ was gastritis $(n=8)$ and esophagitis/ Barrett's esophagus $(n=6)$, but no patient developed upper GI cancer. Binary logistic regression analysis using FC $>50 \mu \mathrm{g} / \mathrm{g}$ as a dependent variable showed that the differences in upper GI disease did not remain after controlling for age, gender, PPI use, and NSAID use (multivariate OR 1.70; 95\% CI: 0.77-3.74). When using FC $>100 \mu \mathrm{g} / \mathrm{g}$ as a dependent variable in the binary logistic model, there was no difference in developing upper GI disease (multivariate OR 2.01 ; 95\% CI: 0.91-4.44). The most common lower GI disease in the group with elevated FC diagnosed in the follow-up period was diverticulitis $(n=4)$ and ileus $(n=3)$ (Table 2).

\section{Inflammatory Bowel Disease}

Two patients were diagnosed with IBD during the 3-year period after their colonoscopy. The FC levels at the initial colonoscopy for these patients were $44 \mu \mathrm{g} / \mathrm{g}$ (Crohn's disease) and $20 \mu \mathrm{g} / \mathrm{g}$ (ulcerative proctitis), respectively.

\section{Cancer}

Eight patients developed cancer in the GI tract during the study. Two patients developed new colorectal cancer, and 3 patients had a relapse of a previously known colorectal cancer. Of these 8 patients, only 2 had a FC level $>50$ $\mu \mathrm{g} / \mathrm{g}$ at the time of the initial colonoscopy. The cancer cases are presented in Table 3.

\section{Death, Stroke, and Myocardial Infarction}

Forty patients (7\%) suffered a stroke, myocardial infarction, or deceased during the study and the composite outcome of these major events were significantly more frequent in the subjects with $\mathrm{FC}>50 \mu \mathrm{g} / \mathrm{g}$ (Table 2). However, in the binary logistical regression model, including age and gender as independent variables, there were no significant differences between subjects with $>50$ $\mu \mathrm{g} / \mathrm{g}$ and subjects with $\leq 50 \mu \mathrm{g} / \mathrm{g}$ (multivariate OR 1.68; 95\% CI: 0.83-3.42). Also, when using FC $>100 \mu \mathrm{g} / \mathrm{g}$ as a dependent variable, there was no difference in the compound variable (multivariate OR 1.80; 95\% CI: $0.87-$ 3.71).

\section{Patients with $F C>200 \mu \mathrm{g} / G$}

Of the 45 patients with a $\mathrm{FC}>200 \mu \mathrm{g} / \mathrm{g}$ and a normal colonoscopy, 5 patients (11\%) were diagnosed with a GI disease in the follow-up period. Three patients were diagnosed with "Gastritis," and 2 patients were diagnosed with Ileus, but there were no patients who developed cancer (Table 3). The median age was significantly higher in the patients with FC $>200 \mu \mathrm{g} / \mathrm{g}$ than the patients with FC $\leq 200 \mu \mathrm{g} / \mathrm{g}$ group ( 69 vs. 63 years; $p<0.001$ ). 


\section{Discussion}

In clinical practice, there is uncertainty in how to interpret a patient with an elevated FC test and without any obvious cause on investigations of the GI tract. We investigated if it was safe to rule out significant GI disease in a patient with an elevated FC test with a normal colonoscopy in clinical practice. In our study that included 585 patients referred for colonoscopy and with a normal colonic investigation, we found that in subjects with FC levels $>50 \mu \mathrm{g} / \mathrm{g}$, there was a significantly higher risk during the following 3 years than an upper GI disease would be diagnosed. However, after controlling for common factors that elevate FC (age, gender, NSAID, and PPI use), this risk was no longer significant. The upper GI diseases diagnosed in the follow-up period were of benign nature (gastritis and gastroesophageal reflux disease), and a delay to diagnosis in these patients was likely of minor clinical significance.

Few studies have investigated the relationship between elevated FC levels, normal colonoscopy, and future GI disease. We only found a small report in the literature (an abstract) on 67 patients with a FC $>50 \mu \mathrm{g} / \mathrm{g}$ and a normal colonoscopy [21]. In that study, patients with FC levels $<225 \mu \mathrm{g} / \mathrm{g}$ did not develop intestinal disease over a period of 3 years, but in patients with FC $>225 \mu \mathrm{g} / \mathrm{g}, 14$ out of 25 patients developed significant GI disease during the 3 -year follow-up period. Nine of the patients in that study developed IBD. However, in our study, only 2 patients in total developed IBD during follow-up, and none of those 2 patients had a FC $>50 \mu \mathrm{g} / \mathrm{g}$.

There are other studies that have focused on slightly elevated FC levels and colonoscopy findings (but without an index colonoscopy) [22, 23]. For example, a study from Scotland [23] investigated the significance of slightly elevated FC levels (in the span 100-200 $\mu \mathrm{g} / \mathrm{g}$ with the Bûhlmann calprotectin ELISA kit) in patients $16-50$ years of age that presented with lower GI symptoms. In that study, the negative predictive value for any GI pathology was $86.7 \%$ during a follow-up of approximately 3 years. If only IBD, advanced adenoma, and colorectal cancer were the target, the negative predictive value was much higher (97.5\%) [23]. Högberg et al. [24] investigated the accuracy of FC to predict a positive diagnosis of IBD, advanced adenoma, and colorectal cancer in primary care in a 2-year follow-up period from the FC test. Using FC $>50 \mu \mathrm{g} / \mathrm{g}$ (CALPRO calprotectin ELISA test), the positive predictive value of $\mathrm{FC}>50 \mu \mathrm{g} / \mathrm{g}$ for any of the diagnosis was $18 \%$ ( 20 out of 119 patients with $\mathrm{FC}>50 \mu \mathrm{g} / \mathrm{g}$ had any of the diagnosis) [24].
Increased FC levels have been strongly associated with colonic disease [25]. However, in the present study, in patients with a normal colonoscopy at baseline, an increased risk for developing lower GI disease during the follow-up period was not found.

Increased FC levels have been found in patients with acute diverticulitis [26], and higher FC levels predicted recurrence of colonic diverticulitis in patients suffering from an episode of acute uncomplicated diverticulitis [27]. In the present study, 13 patients developed clinical diverticulitis during the follow-up period, but only 4 of these patients had elevated FC levels at the time of the index colonoscopy. Overall, the presence of colonic diverticulosis was associated with higher FC levels, but in the same patient population, we previously showed that when controlling for age, there was no association between FC levels and the finding of colonic diverticulosis on colonoscopy [19]. Consistent with this finding, Tursi et al. [26] did not detect an association between FC levels and asymptomatic diverticular disease.

Increased FC levels have been associated with colorectal cancer [28]. At the index colonoscopy, approximately $2-13 \%$ of adenomas are missed [29]. In our study, an elevated FC test in combination with a normal colonoscopy was not associated with a risk of colorectal cancer or other GI cancers in the following 3 years after the colon investigation. Overall, there were 8 patients who developed any GI cancer in the follow-up period. Six of these patients had a normal FC test at the index colonoscopy, and 2 patients had only slightly elevated FC levels (i.e., 65 and $150 \mu \mathrm{g} / \mathrm{g}$, respectively).

Inflammation plays a role in the pathogenesis of cardiovascular disease [30]. Several studies have implied that serum calprotectin is associated with the pathogenesis of coronary artery disease, and it has the potential to discriminate between stable and unstable coronary artery disease [31-35]. Therefore, we compared the incidence of cardiovascular events and death in the follow-up period between the subjects with low versus high FC levels. In our study, a composite outcome of death, stroke, and myocardial infarction showed that the group with elevated FC levels was more than twice as likely to suffer from any of these events. However, when controlling for age and gender, there was no difference in risk between the patients with high and low FClevels. This implies that age and male gender, and not FC levels are risk factors for cardiovascular events and death among the patients in our study.

There are some limitations in our study design. Although we included a large group of patients, the study 
was underpowered (type 2 error) for the development of several GI diseases (e.g., IBD) in the follow-up period. However, the overall risk for the composite variables lower, respectively, upper GI disease, the power of the study was acceptable. An inclusion criterion was a patient being referred for colonoscopy. Therefore, our results are applicable mainly to patients referred to colonoscopy and may not be generalized to the general population. For example, the subjects included in the study were older than in the general population. On the other hand, our study population reflects what is seen in daily clinical practice.

After the index colonoscopy, no active follow-up of the patients was performed. Instead, the study was a pragmatic study that aimed to show what happened in real life. For example, we have no information of the upper GI or small bowel before or at the time of the FC test, and additional investigations of the GI tract were dependent on the decisions made in clinical practice. The diagnosis was based on clinical judgment that in turn was based on the history in combination with objective data, and in some patients, the diagnosis was not confirmed by histology or radiologic findings.

Unfortunately, we have no data on the subjects who did not participate in the study. For some patients, we cannot rule out that it could be differences in age, socioeconomic status, and perhaps other factors between "participants" and "non-participants."

The strength of our study is that we measured FC before and in close proximity to the performed colonoscopy (just before the bowel preparation), which makes it somewhat certain that our patients had the FC test at the time of the endoscopy. In addition, the endoscopists and the pathologists were blinded to the result of the FC test. Furthermore, strength of our study is that at the time of study, there was no private endoscopy unit in the catchment area of Umeå, and therefore, the study mirrors "all patients" referred to colonoscopy in the catchment area. The only exclusion criteria were known GI disease, if the colonoscopy was planned to be scheduled in $<1$ week from referral, or if the patient had any impaired mental ability, dementia, or low-performance status that made it difficult to provide a stool sample and/or to fill in the questionnaires. Finally, all patients who participated in the study stayed residing in the catchment area throughout the study period, which strengthens the retrospective observation analysis.

In summary, in patients with a normal colonoscopy, a simultaneously measured increased FC level was not associated with an increased risk of developing GI disease during the following 3 years. We argue that it is safe to rule out colonic disease in patients referred to colonoscopy with increased FClevels and a normal colonic investigation.

\section{Acknowledgements}

We like to give our thanks to the staff of the Endoscopic unit at Umeå University Hospital, Umeå, Sweden for their efforts and cooperation.

\section{Statement of Ethics}

This study was approved by the Research Ethics Committee of Umeå University (Dnr 07-054M). All patients gave their written consent to participate in the study, and this was done before they started their bowel preparation for the colonoscopy.

\section{Conflict of Interest Statement}

The authors have no conflict of interest to disclose.

\section{Funding Sources}

This study was funded by the Region of Västerbotten County Council, Sweden.

\section{Author Contributions}

H.H., D.L., and P.K. designed the study. H.H. did the initial data collection, data analysis, and wrote the first manuscript. D.L. and P.K. further analyzed the data, revised the manuscript, and drafted the final manuscript.

References

Inflamm Intest Dis 2021;6:101-108

Caviglia GP, Pantaleoni S, Touscoz GA, Adriani A, Rosso C, Smedile A, et al. Fecal calprotectin is an effective diagnostic tool that differentiates inflammatory from functional intestinal disorders. Scand J Gastroenterol. 2014 Dec;49(12):1419-24.

2 Kalantari H, Taheri A, Yaran M. Fecal calprotectin is a useful marker to diagnose ulcerative colitis from irritable bowel syndrome. Adv Biomed Res. 2015;4:85.

3 D'Angelo F, Felley C, Frossard JL. Calprotectin in daily practice: where do we stand in 2017? Digestion. 2017;95(4):293-301.

4 Pruenster M, Vogl T, Roth J, Sperandio M S100A8/A9: from basic science to clinical application. Pharmacol Ther. 2016 Nov; 167: $120-31$. 
5 Tibble JA, Sigthorsson G, Foster R, Forgacs I, Bjarnason I. Use of surrogate markers of inflammation and Rome criteria to distinguish organic from nonorganic intestinal disease. Gastroenterology. 2002 Aug;123(2):450-60.

6 Costa F, Mumolo MG, Bellini M, Romano MR, Ceccarelli L, Arpe P, et al. Role of faecal calprotectin as non-invasive marker of intestinal inflammation. Dig Liver Dis. 2003 Sep; 35(9):642-7.

7 Gisbert JP, McNicholl AG. Questions and answers on the role of faecal calprotectin as a biological marker in inflammatory bowel disease. Dig Liver Dis. 2009 Jan;41(1):56-66.

8 Manceau H, Chicha-Cattoir V, Puy H, Peoc'h $\mathrm{K}$. Fecal calprotectin in inflammatory bowel diseases: update and perspectives. Clin Chem Lab Med. 2017 Mar 1;55(4):474-83.

9 Tibble J, Teahon K, Thjodleifsson B, Roseth A, Sigthorsson G, Bridger S, et al. A simple method for assessing intestinal inflammation in Crohn's disease. Gut. 2000 Oct;47(4):50613.

10 Mao R, Xiao YL, Gao X, Chen BL, He Y, Yang $\mathrm{L}$, et al. Fecal calprotectin in predicting relapse of inflammatory bowel diseases: a metaanalysis of prospective studies. Inflamm Bowel Dis. 2012 Oct; 18(10):1894-9.

11 Kwapisz L, Mosli M, Chande N, Yan B, Beaton M, Micsko J, et al. Rapid fecal calprotectin testing to assess for endoscopic disease activity in inflammatory bowel disease: a diagnostic cohort study. Saudi J Gastroenterol. 2015 Nov-Dec;21(6):360-6.

12 Jain S, Kedia S, Bopanna S, Sachdev V, Sahni $P$, Dash NR, et al. Faecal calprotectin and UCEIS predict short-term outcomes in acute severe colitis: prospective cohort study. J Crohns Colitis. 2017 Oct 27;11(11):1309-16.

13 Klingberg E, Carlsten H, Hilme E, Hedberg M, Forsblad-d'Elia H. Calprotectin in ankylosing spondylitis-frequently elevated in feces, but normal in serum. Scand J Gastroenterol. 2012 Apr;47(4):435-44.

14 Vaos G, Kostakis ID, Zavras N, Chatzemichael A. The role of calprotectin in pediatric disease. Biomed Res Int. 2013;2013:542363.

15 Andreasson K, Saxne T, Scheja A, Bartosik I, Mandl T, Hesselstrand R. Faecal levels of calprotectin in systemic sclerosis are stable over time and are higher compared to primary Sjogren's syndrome and rheumatoid arthritis. Arthritis Res Ther. 2014 Feb 6;16(1):R46.
16 Rutka M, Bor R, Bálint A, Fábián A, Milassin Á, Nagy F, et al. Diagnostic accuracy of five different fecal markers for the detection of precancerous and cancerous lesions of the colorectum. Mediators Inflamm. 2016;2016: 2492081.

17 Tibble JA, Sigthorsson G, Foster R, Scott D, Fagerhol MK, Roseth A, et al. High prevalence of NSAID enteropathy as shown by a simple faecal test. Gut. 1999 Sep;45(3):362-6.

18 Poullis A, Foster R, Mendall MA, Shreeve D, Wiener K. Proton pump inhibitors are associated with elevation of faecal calprotectin and may affect specificity. Eur J Gastroenterol Hepatol. 2003 May;15(5):573-4;

19 Lundgren D, Eklöf V, Palmqvist R, Hultdin J, Karling P. Proton pump inhibitor use is associated with elevated faecal calprotectin levels. A cross-sectional study on subjects referred for colonoscopy. Scand J Gastroenterol. 2019 Feb;54(2):152-7.

20 Loniewska B, Adamek K, Wegrzyn D, Kaczmarczyk M, Skonieczna-Zydecka K, Clark J, et al. Analysis of faecal zonulin and calprotectin concentrations in healthy children during the first two years of life. An observational prospective cohort study. J Clin Med. 2020 Mar 12;9(3):777.

21 Mohammed N, Smale S. PTU-125 positive calprotectin but negative investigations-what next? Gut. 2012 Jul;61(Suppl 2):2-A36.

22 Eklof V, Lofgren-Burstrom A, Zingmark C, Edin S, Larsson P, Karling P, et al. Cancerassociated fecal microbial markers in colorectal cancer detection. Int J Cancer. 2017 Dec 15;141(12):2528-36

23 Seenan JP, Thomson F, Rankin K, Smith K, Gaya DR. Are we exposing patients with a mildly elevated faecal calprotectin to unnecessary investigations? Frontline Gastroenterol. $2015 \mathrm{Jul} ; 6(3): 156-60$.

24 Hogberg C, Karling P, Rutegard J, Lilja M. Diagnosing colorectal cancer and inflammatory bowel disease in primary care: the usefulness of tests for faecal haemoglobin, faecal calprotectin, anaemia and iron deficiency. A prospective study. Scand J Gastroenterol. 2017 Jan;52(1):69-75.

25 Manz M, Burri E, Rothen C, Tchanguizi N, Niederberger C, Rossi L, et al. Value of fecal calprotectin in the evaluation of patients with abdominal discomfort: an observational study. BMC Gastroenterol. 2012 Jan 10;12:5.
26 Tursi A, Brandimarte G, Elisei W, Giorgetti GM, Inchingolo CD, Aiello F. Faecal calprotectin in colonic diverticular disease: a casecontrol study. Int J Colorectal Dis. 2009 Jan; 24(1):49-55.

27 Tursi A, Elisei W, Picchio M, Brandimarte G. Increased faecal calprotectin predicts recurrence of colonic diverticulitis. Int J Colorectal Dis. 2014 Aug;29(8):931-5.

28 Tibble J, Sigthorsson G, Foster R, Sherwood R, Fagerhol M, Bjarnason I. Faecal calprotectin and faecal occult blood tests in the diagnosis of colorectal carcinoma and adenoma. Gut. 2001 Sep;49(3):402-8.

29 van Rijn JC, Reitsma JB, Stoker J, Bossuyt PM, van Deventer SJ, Dekker E. Polyp miss rate determined by tandem colonoscopy: a systematic review. Am J Gastroenterol. $2006 \mathrm{Feb}$; 101(2):343-50

30 Libby P, Ridker PM, Hansson GK; Leducq Transatlantic Network on Atherothrombosis. Inflammation in atherosclerosis: from pathophysiology to practice. J Am Coll Cardiol. 2009 Dec 1;54(23):2129-38.

31 Healy AM, Pickard MD, Pradhan AD, Wang Y, Chen Z, Croce K, et al. Platelet expression profiling and clinical validation of myeloidrelated protein-14 as a novel determinant of cardiovascular events. Circulation. 2006 May 16;113(19):2278-84.

32 Altwegg LA, Neidhart M, Hersberger M, Müller S, Eberli FR, Corti R, et al. Myeloid-related protein $8 / 14$ complex is released by monocytes and granulocytes at the site of coronary occlusion: a novel, early, and sensitive marker of acute coronary syndromes. Eur Heart J. 2007 Apr;28(8):941-8.

33 Morrow DA, Wang Y, Croce K, Sakuma M, Sabatine MS, Gao H, et al. Myeloid-related protein $8 / 14$ and the risk of cardiovascular death or myocardial infarction after an acute coronary syndrome in the pravastatin or atorvastatin evaluation and infection therapy: thrombolysis in myocardial infarction (PROVE IT-TIMI 22) trial. Am Heart J. 2008 Jan;155(1):49-55.

34 Katashima T, Naruko T, Terasaki F, Fujita M, Otsuka K, Murakami S, et al. Enhanced expression of the S100A8/A9 complex in acute myocardial infarction patients. Circ J. 2010 Apr;74(4):741-8.

35 Larsen SB, Grove EL, Pareek M, Kristensen SD, Hvas AM. Calprotectin and platelet aggregation in patients with stable coronary artery disease. PLoS One. 2015;10(5):e0125992. 